\title{
Silicate weathering in anoxic marine sediments
}

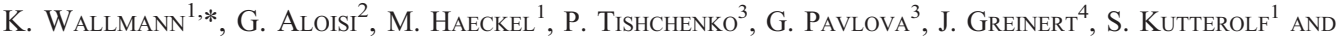 \\ A. EISENHAUER ${ }^{1}$ \\ ${ }^{1}$ IFM-GEOMAR Leibniz Institute of Marine Sciences, Wischhofstrasse 1-3, 24148 Kiel, Germany \\ ${ }^{2}$ Laboratoire de Paléoenvironnements et Paléobiosphère, Université Claude Bernard - Lyon I, 2, rue Dubois, F- \\ 69622 Villeurbanne cedex, France \\ ${ }^{3}$ Pacific Oceanological Institute (POI), 43, Baltiyskaya Street, 690041 Vladivostok, Russia \\ ${ }^{4}$ Renard Centre of Marine Geology Department of Geology and Soil Science, Ghent University, Krijgslaan 281 s. 8 \\ B-9000 Ghent, Belgium
}

\section{Introduction}

Two sediment cores retrieved at the northern slope of Sakhalin Island, Sea of Okhotsk, were analysed for biogenic opal, organic carbon, carbonate, sulphur, major element concentrations, mineral contents and dissolved substances including nutrients, sulphate, methane, major cations, humic substances and total alkalinity. Down-core trends in mineral abundance suggest that plagioclase feldspars and other reactive silicate phases (olivine, pyroxene, volcanic ash) are transformed into smectite in the methanogenic sediment sections. The element ratios $\mathrm{Na} / \mathrm{Al}$, $\mathrm{Mg} / \mathrm{Al}$ and $\mathrm{Ca} / \mathrm{Al}$ in the solid phase decrease with sediment depth indicating a loss of mobile cations with depth and producing a significant down-core increase in the chemical index of alteration. Pore waters separated from the sediment cores are highly enriched in dissolved $\mathrm{Mg}$, total alkalinity, humic substances and boron. The large contents of dissolved organic carbon in the deeper methanogenic sediment sections (50-150 $\mathrm{mg} \mathrm{dm}^{-3}$ ) may promote the dissolution of silicate phases through complexation of $\mathrm{Al}^{3+}$ and other structure-building cations. A non-steady state transport-reaction model was developed and applied to evaluate the down-core trends observed in the solid and dissolved phases. Dissolved $\mathrm{Mg}$ and total alkalinity were used to track the in-situ rates of marine silicate weathering since thermodynamic equilibrium calculations showed that these tracers are not affected by ion exchange processes with sediment surfaces. The modelling showed that silicate weathering is limited to the deeper methanogenic sediment section whereas

*E-mail: kwallmann@ifm-geomar.de

DOI: 10.1180/minmag.2008.072.1.363 reverse weathering was the dominant process in the overlying surface sediments. Depth-integrated rates of marine silicate weathering in methanogenic sediments derived from the model (81.4-99.2 mmol CO $\mathrm{CO}_{2} \mathrm{~m}^{-2} \mathrm{yr}^{-1}$ ) are smaller than the marine weathering rates calculated from the solid phase data $(198-245 \mathrm{mmol}$ $\mathrm{CO}_{2} \mathrm{~m}^{-2} \mathrm{yr}^{-1}$ ) suggesting a decrease in marine weathering over time. The production of $\mathrm{CO}_{2}$ through reverse weathering in surface sediments (4.22-15.0 mmol CO $\mathrm{CO}_{2}^{-2} \mathrm{yr}^{-1}$ ) is approximately one order of magnitude smaller than the weathering-induced $\mathrm{CO}_{2}$ consumption in the underlying sediments. The evaluation of pore water data from other continental margin sites shows that silicate weathering is a common process in methanogenic sediments. The global rate of $\mathrm{CO}_{2}$ consumption through marine silicate weathering estimated here as 5-20 Tmol $\mathrm{CO}_{2} \mathrm{yr}^{-1}$ is as large as the global rate of continental silicate weathering. Details of the present work can be found in (Wallmann et al., 2008).

\section{Methods}

Sediments were taken by piston coring at the northern continental slope of Sakhalin Island during cruise SO178 with RV SONNE in July-September 2004. Core KL-13-6 was retrieved at a water depth of $713 \mathrm{~m}$ (position: $52^{\circ} 43.88^{\prime} \mathrm{N}$; $\left.144^{\circ} 42.65^{\prime} \mathrm{E}\right)$ while core KL-29-2 was taken further north $\left(53^{\circ} 50.00^{\prime} \mathrm{N}\right.$; $\left.144^{\circ} 14.23^{\prime} \mathrm{E}\right)$ at $771 \mathrm{~m}$ water depth. Pore fluids were processed and analysed as previously described (Wallmann et al., 2006). Solids were characterized by polarization microscopy, XRD and XRF. A numerical transport-reaction model was applied to the pore water data set to calculate 
rates of organic matter degradation, sulphate reduction, methane production, anaerobic oxidation of methane, carbonate precipitation and dissolution, and silicate weathering. Within this modelling framework, down-core changes in the rate of silicate weathering were traced and tracked applying the concentration profiles of dissolved $\mathrm{Mg}$ and total alkalinity (Wallmann et al., 2008).

\section{Results and discussion}

Rapidly accumulating sediments composed of biogenic opal, organic matter, plagioclase feldspars, olivine, pyroxene, volcanic glass, clay minerals and other products of continental weathering are deposited at the Sakhalin slope. Reverse weathering occurring in the upper section of the studied sediment cores induces the fixation of dissolved cations $\left(\mathrm{Mg}^{2+}, \mathrm{Na}^{+}, \mathrm{K}^{+}, \mathrm{Li}^{+}\right)$in authigenic clays and the consumption of carbonate alkalinity. Ammonium released during the breakdown of organic matter is adsorbed at sediment surfaces replacing adsorbed $\mathrm{Ca}^{2+}$ and $\mathrm{Na}^{+}$ions that are released into the pore water via cation exchange. Reactive silicates (plagioclase feldspars, olivine, pyroxene, volcanic glass) are partly dissolved and transformed into cationdepleted silicate phases in the deeper methanogenic sediment sections (Fig. 1).

The marine weathering of these silicates induces the release of $\mathrm{Mg}^{2+}, \mathrm{Ca}^{2+}$ and $\mathrm{Na}^{+}$as well as the formation of authigenic carbonates (Fig. 2). The $\mathrm{CO}_{2}$ which formed during carbonate precipitation and breakdown of organic matter in methanogenic sediments is completely neutralized during silicate weathering. Rates of marine silicate weathering are one order of magnitude greater than the rates of reverse weathering and cation exchange in Sakhalin slope sediments and significantly larger than the rates of continental silicate weathering in the hinterland drained by the Amur River.

Pore water data obtained at other productive continental margin sites demonstrate that silicate weathering is a common process in methanogenic sediments with high metabolic activity. Most of the $\mathrm{CO}_{2}$ formed during the anaerobic breakdown of organic matter is converted into alkalinity and authigenic carbonates (Wallmann et al., 2008). Thus, silicate weathering in methanogenic marine sediments constitutes a significant sink for $\mathrm{CO}_{2}$ and a source for carbonate alkalinity that needs to be included in future budgets of the global and marine carbon cycles. The global rate of marine silicate weathering estimated as 5-20 Tmol $\mathrm{CO}_{2} \mathrm{yr}^{-1}$ may be as high as the global $\mathrm{CO}_{2}$ consumption through continental weathering.

\section{Conclusions and perspectives}

Marine sediments have previously been regarded as important $\mathrm{CO}_{2}$ sinks since large amounts of organic carbon formed though photosynthesis are ultimately buried at the seafloor. It has, however, been ignored that the degradation of organic matter in anoxic sediments works in a fundamentally different way than aerobic degradation. While aerobic respiration recycles $\mathrm{CO}_{2}$ into the oceans and atmosphere, anaerobic degradation, coupled to marine silicate weathering, produces large amounts of carbonate alkalinity and authigenic carbonates. Thus, $\mathrm{CO}_{2}$ fixed in organic matter during primary production is not recycled but transformed into other carbon

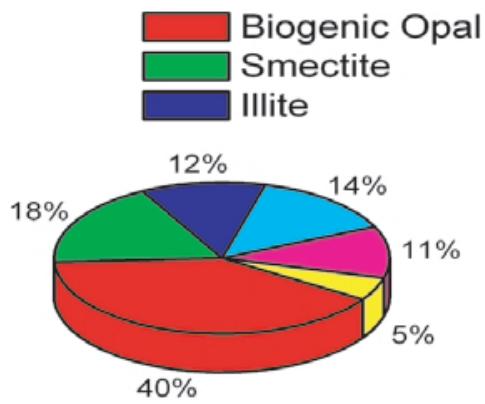

Core top KL-29-2
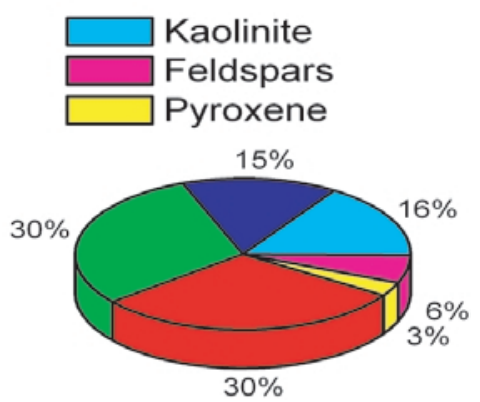

Core base KL-29-2

FIG. 1. Composition of surface sediments and core base sediments retrieved at the northern Sakhalin slope (KL-29-2). 


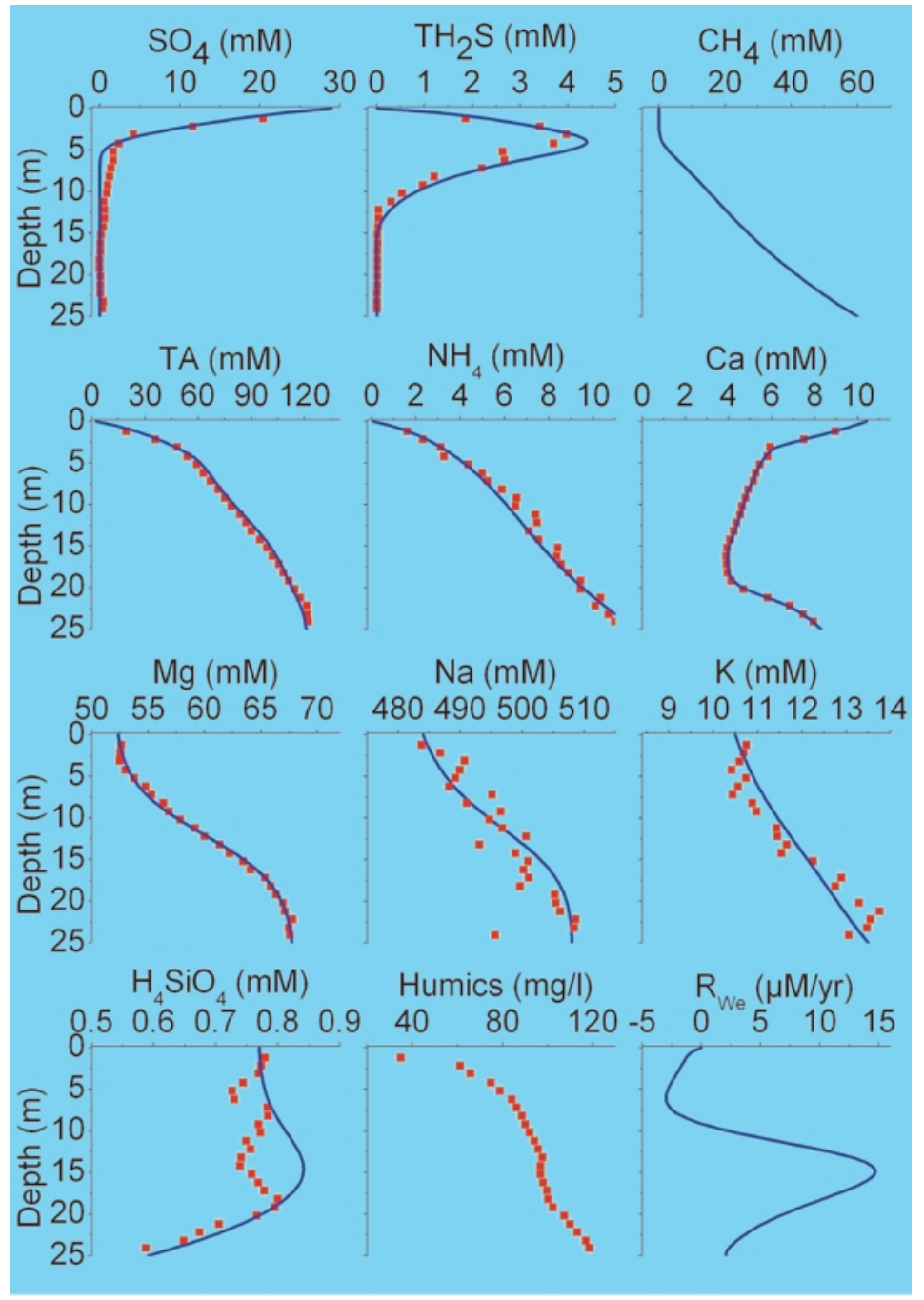

FIG. 2. Composition of pore fluids in sediments retrieved at the northern Sakhalin slope (KL-29-2). Red squares indicate data and blue curves represent the model results. TA is total alkalinity and $\mathrm{R}_{\mathrm{WE}}$ gives the rate of $\mathrm{CO}_{2}$ consumption via silicate weathering.

compounds $\left(\mathrm{HCO}_{3}^{-}, \mathrm{CaCO}_{3}\right)$ during anoxic diagenesis. The global rate of carbon transformation in anoxic sediments is estimated here to be

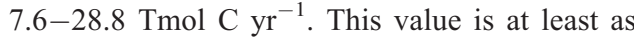
large as the global rate of organic carbon burial in marine sediments $\left(13 \mathrm{Tmol} \mathrm{C} \mathrm{yr}^{-1}\right.$; (Hedges and Keil, 1995) and therefore this previously ignored $\mathrm{CO}_{2}$ sink has to be considered in future budgets of global carbon cycling.

The total alkalinity (TA) inventory of the oceans is believed to be controlled by riverine
$\mathrm{HCO}_{3}^{-}$inputs and through carbonate burial at the seafloor. The alkalinity budget of the Holocene ocean seems to be out of balance since TA removal through carbonate burial (48 $\mathrm{Tmol} \mathrm{yr}^{-1}$; Berner and Berner, 1996) is larger than the riverine TA flux (38 Tmol $\mathrm{yr}^{-1}$; Berner and Berner, 1996). Part of this imbalance is caused by glacial to interglacial sea-level changes affecting carbonate burial on the continental shelves. The TA generated in anoxic marine sediments through silicate weathering and sulphur burial 


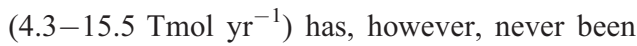
considered and may in fact account for a major portion of the apparent TA imbalance.

Marginal seas are known to act as $\mathrm{CO}_{2}$ pumps taking up atmospheric $\mathrm{CO}_{2}$ and exporting carbonate alkalinity into the open ocean (Tsunogai et al., 1999). This continental-shelf pump operating in the Sea of Okhotsk (Otsuki et al., 2003) and in other marginal seas (Thomas et al., 2004) may remove large quantities of anthropogenic $\mathrm{CO}_{2}$ from the atmosphere. Anoxic sediments that are preferentially deposited at productive continental margins may contribute to the $\mathrm{CO}_{2}$ uptake through marine silicate weathering and sulphur burial.

The global rate of authigenic carbonate burial in anoxic marine sediments estimated here as 3.3-13.3 Tmol $\mathrm{CaCO}_{3} \mathrm{yr}^{-1}$ approaches the modern rate of pelagic carbonate burial (10 Tmol $\mathrm{CaCO}_{3} \mathrm{yr}^{-1}$; (Archer, 1996). Productive continental margins with high rates of terrigenous sedimentation are thus important and previously ignored sites of carbonate accumulation. Approximately $50 \%$ of the $\mathrm{Ca}$ buried in authigenic carbonates originates from seawater such that the $\mathrm{Ca}$ balance of the ocean is also affected by anoxic diagenesis.

In contrast to continental weathering, marine weathering is not directly coupled to average global surface temperature and atmospheric $p \mathrm{CO}_{2}$. Carbon transformations in anoxic sediments are rather fueled by the deposition of particulate organic matter and reactive silicate phases. As a result the consumption of $\mathrm{CO}_{2}$ in these sediments is controlled by continental erosion and marine productivity. The negative climate feedback established by the temperatureand $p \mathrm{CO}_{2}$-dependent rate of continental weathering (Berner, 2004) is weakened by marine weathering processes since reactive silicate phases which are not consumed on land may be weathered in methanogenic sediments. Marine weathering might, thus, amplify climate change on geological time scales and could, for example, contribute to the draw-down of atmospheric $\mathrm{CO}_{2}$ observed during the late Cenozoic and glacial periods of the Quaternary.

The results presented in this study also have major implications for the applied geosciences. Natural gas hydrates and gas reservoirs formed in marine sediments contain large amounts of $\mathrm{CH}_{4}$ but usually much less $\mathrm{CO}_{2}$ even though both gases are produced at equi-molar rates during the break- down of organic matter. Small $\mathrm{CO}_{2}$ contents in natural gas and gas hydrates may be caused by marine weathering processes. Hence, the $\mathrm{CO}_{2}$ consumption via marine silicate weathering should be considered in basin modelling to better predict the $\mathrm{CO}_{2}$ contents of economically important natural gas and gas hydrate reservoirs. Moreover, marine sediments are increasingly used for the disposal of $\mathrm{CO}_{2}$ separated from natural gas and in coal power plants (House et al., 2006). The results presented in this study imply that terrigenous sediments with large contents of reactive silicate phases might be well-suited for sites of $\mathrm{CO}_{2}$ disposal since $\mathrm{CO}_{2}$ may be rapidly neutralized by marine silicate weathering.

\section{References}

Archer, D.E. (1996) An atlas of the distribution of calcium carbonate in sediments of the deep sea. Global Biogeochemical Cycles, 10, 159-174.

Berner, R.A. (2004) The Phanerozoic Carbon Cycle: $\mathrm{CO}_{2}$ and $\mathrm{O}_{2}$. Oxford University Press.

Berner, E.K. and Berner, R.A. (1996) Global Environment: Water, Air and Geochemical Cycles. Prentice Hall.

Hedges, J.I. and Keil, R.G. (1995) Sedimentary organic matter preservation: an assessment and speculative synthesis. Marine Chemistry, 49, 81-115.

House, K.Z., Schrag, D.P., Harvey, C.F. and Lackner, K.S. (2006) Permanent carbon dioxide storage in deep-sea sediments. PNAS, 103, 12291-12295.

Otsuki, A.S., Watanabe, S. and Tsunogai, S. (2003) Adsorption of atmospheric $\mathrm{CO}_{2}$ and its transport to the intermediate layer in the Okhotsk Sea. Journal of Oceanography, 59, 709-717.

Thomas, H., Bozec, Y., Elkalay, K. and De Baar, H.J.W. (2004) Enhanced open ocean storage of $\mathrm{CO}_{2}$ from shelf sea pumping. Science, 304, 1005-1008.

Tsunogai, S., Watanabe, S. and Sato, T. (1999) Is there a "continental shelf pump" for the absorption of atmospheric $\mathrm{CO}_{2}$ ? Tellus, B 51, 701-712.

Wallmann, K., Aloisi, G., Haeckel, M., Obzhirov, A., Pavlova, G. and Tishchenko, P. (2006) Kinetics of organic matter degradation, microbial methane generation, and gas hydrate formation in anoxic marine sediments. Geochimica et Cosmochimica Acta, 70, 3905-3927.

Wallmann, K., Aloisi, G., Haeckel, M., Tishchenko, P., Pavlova, G., Greinert, J., Kutterolf, S. and Eisenhauer, A. (2008) Silicate weathering in anoxic marine sediments. Geochimica et Cosmochimica Acta, 72, 3067-3090. 